of the retina illuminated either not at all or very faintly, but whose immediate neighbourhood was brightly illuminated, gave, in the negative after-image, a much stronger brightness than one, the neighbourhood of which was not so illuminated. The phenomena of contrast show, on the other hand, that the light-perception of a weakly illuminated part of the retina is diminished when its surrounding part is brightly illuminated. Thus the lowering of the perception of brightness (or excitement) during the observation of an object, corresponds to the raising of this perception in the after-image, so that the successive light-induction appears as the opposite or reversal (Gegensatz) of the simultaneous contrast-action. And the latter may be denoted as a simultaneous negative light-induction.

It is, therefore, easy to imagine an internal causal connection between both phenomena, and to consider the lowering of the light-perception (excitability) which takes place during the contrast, as the cause of the raising of the perception which takes place afterwards.

The third memoir treats of "Simultaneous Light-Induction" and "Successive Contrast." To illustrate the former, look fixedly at any point in a line dividing a black space from a white one; after looking some time you will see that the originally deep black begins to lighten into gray; the brightening is the greatest close to the division line, and diminishes farther away, but after sufficiently long observation it will extend more or less over the whole black field. A contrary effect takes place, but less prominently, in the other half, the white darkening in a similar way.

This appearance is usually explained in the following half physiological, half psychological way. From the increasing fatigue of the retina, the white sensation becomes gradually weaker, and, as a consequence of this, the contrast action between the white and the black becomes weaker, and the latter appears lighter, through the same false judgment invoked to explain contrasts generally.

To show the insufficiency of this explanation the following experiment is proposed. Put a strip of black velvet on a white ground, well lighted by a gas flame; after observing it steadfastly for a time gradually diminish the light, and it will be seen that the black strip becomes brighter, and the white ground darker, until at length the former appears actually lighter than the latter. If the explanation is applied to this it must be assumed that the fatigue of the retina has become so great that the moderated white produces actually a less powerful impression than the black stripe, which gives out light of very small intensity, or in other words, that the power of the retina is so crippled that a moderate light is no longer able to produce an impression equal to the inner selfillumination of the unfatigued organ. This can be also shown by another trial which is described.

A further experiment enables a direct comparison to be made. In the middle of a broad white stripe laid on a black ground, cut a longitudinal opening; this will show an internal black stripe, surrounded by a white surface which is again surrounded by a black ground: then fix the eyes on the middle of the figure, and, after observing some time, gradually reduce the light. It will soon be found that the black internal stripe appears lighter than the external black ground, although both are objectively equally dark, and the parts of the retina brought into action are, as it is said, equally free from fatigue.

The changes consequent on the reduction of the illumination show that the simultaneous light-induction passes over into the successive, the latter being, indeed, only a more clearly manifested continuation of the former. The connection of the three phenomena hitherto treated of may be illustrated simply as follows :-When you first observe a line of division between dark and light, the dark part, especially near the division, appears darker than it would do if the white were absent; this is simultaneous contrast. Continue the fixed observation a longer time, and the darkening gradually changes to a contrary effect of brightening, which also is most powerful near the division; this is simultaneous light-induction. Lastly, close and darken the eyes, and this brightened space continues a long time visible in the after-image. This is successive light-induction.

The last of the subjective phenomena treated of by the author he calls "Successive Light Contrast." It differs from the three last mentioned in that, while they all refer to the comparison of one visual space with another close adjoining, this refers to a comparison of the impressions derived from the same space at two successive times. The simplest example is as follows:-Put a strip of white paper on a black ground, and observe it steadfastly for a time ; then let it be suddenly removed, keeping the eyes fixed on the same spot. A negative after-image will result, of a changeable character, but showing generally a space corresponding to the paper, much darker than the already dark ground. This is very striking; an inexperienced observer will be loth to believe that he can see anything darker than the blackest velvet; but there can be no mistake about the impression conveyed. The usual explanation of this is that the part of the retina stimulated by the white paper is more fatigued than the rest, and therefore, after it is removed, is less sensitive to the faint light given off by the black ground, making it thus appear still fainter. The author deems this explanation insufficient, as it is inconsistent with many of the changing phases observed in the after-image; and he describes several other experiments to support this view. He points out that the "successive light-induction," before described, may play an important part in these phenomena, but he does not attempt here to give any complete explanation of them.

It is pointed out at the close of this part of the subject that many of the experiments may be made with colours, instead of with simple light and shade, it being understood that black and white hold the same relation to each other, for this purpose, as blue and yellow, or red and green.

(To be continued.)

WILLIAM POLE.

\section{ALFRED HENRY GARROD}

$\mathrm{I}^{\mathrm{T}}$ has seldom been our lot to have to record the premature close of a career so full of promise as that which ended with the death of Alfred Henry Garrod, at his father's house in Harley Street, on Friday last, October I7. The son of an eminent physician, Dr. Alfred Baring Garrod, F.R.S., he was born in London on May I8, 1846, received a medical education at King's College, London, and in 1868 entered St. John's College, Cambridge. He graduated (B.A.) in $187 \mathrm{r}$, taking the highest place in the natural science tripos. In due course he took his M.A. degree, and was elected a Fellow of his college in 1873 His earliest scientific predilections were chiefly for mathematics and physics, and the knowledge of these subjects which he acquired when a student was of great value to him in his biological researches. The mechanics of physiology was the subject to which he first turned his attention as a scientific investigator, and, while still an undergraduate, he communicated a paper on the cause of the diastole of the ventricles of the heart to the Fournal of Anatomy (vol. iii., 1869). About the same time he sent to the Royal Society the results of an interesting series of experiments made upon himself with a view of ascertaining the causes of the minor fluctuations in the temperature of the human body while at rest, from which he concluded that these fluctuations mainly result from alterations in the amount of blood exposed at the surface to the influence of absorbing and conducting 
media. These were published in the Proceedings of the Royal Society, vol. xvii., I869. A series of papers in the Proceedings of the Royal Society and in the Fournal of Anatomy followed, giving the result of observations upon the circulation of the blood, conducted with great ingenuity by means of the sphygmograph, aided by various modifications and improvements upon the original instrument cations and improvemd mechanical skill. It is, indeed, probable that physiology is the subject to which he would most willingly have devoted his attention had not his energies been turned to the pursuit of morphology by his receiving the appointment, in January, 1872 , of Prosector to the Zoological Society. This appointment is one which, perhaps more than any now existing, comes near to an ideal endowment of research. An unlimited amount of new material is placed in the hands of its occupant there are no duties beyond those of making and recording original observations, and ample facilities are given for the publication and illustration of all the observations made. To the efficient performance of the duties of this office Mr. Garrod applied himself with great energy and zeal, as testified by his numerous contributions upon the comparative anatomy of the vertebrate animals, which have enriched the publications of the Society, from the date of his appointment to the present time. He devoted great attention to the anatomy of birds, hitherto too much neglected, and his observations upon their myology and visceral anatomy were beginning to throw some light upon the very difficult and obscure subject of the mutual affinities of the members of this class. The curious and most unexpected variations in structure often revealed in the dissection of species thought to be closely allied, soon convinced him of the necessity of far more extended and minute observations than had previously been made, and those who closely watched his work and knew that besides the observations he had had time to complete and publish, he had already accumulated a vast mass of facts, partly in notes and drawings and partly in the stores of his memory, feel most keenly how much has been lost by his early death.

His eagerness in acquiring knowledge was only equalled by his activity in imparting it to others, and he had a remarkably easy and lucid method of explaining, even to an uninstructed audience, difficult problems of physiology or anatomy. With the black-board or some ingeniously contrived diagram or mechanical illustration, he was never at a loss to make his hearers comprehend his meaning. These great and varied powers probably tempted him to overtask his strength. Not content with his work at the Zoological Society, he sought for and obtained the Professorship of Zoology and Comparative Anatomy at King's College, in 1874 , and the Fullerian Professorship of Physiology at the Royal Institution in 1876. He was also appointed one of the Examiners in the Natural Science Tripos at Cambridge in 1875 , and was for several years a constant contributor to this journal. In 1876 , when be had but just completed his thirtieth year, he was elected a Fellow of the Royal Society.

In the simple and single-hearted devotion to the sciences he cultivated, he was without a particle of jealousy or mistrust of others, but was always anxious to assist those who were working in the same direction, and his room at the Zoological Gardens was gradually becoming the profitable resort of many of the younger workers at comparative anatomy, who were encouraged in their labours by his advice and example.

Up to little more than a year ago he was apparently in the enjoyment of vigorous health, but symptoms of the insidious disease, phthisis, which terminated his existence, then for the first time showed themselves. Through the gradual decline of his powers, and amid considerable suffering, borne with the greatest patience and calmness, he continued to the last to spend all his remaining strength in making the knowledge which he had acquired available for the instruction of those that should come after him.

W. H. F.

JOHN MIERS, F.R.S.
1 HIS well-known botanist, whose death took place on
the I7th inst., was born in London on August 25, 1789, of Yorkshire parents. After leaving August 25, devoted his time to the study of mineralogy and chemistry, in which latter science he made a series of important researches, but it was only subsequently during his long residence in South America that he acquired his taste for botanical knowledge, and by making dissections and drawings of plants he became a botanist. In 1825 he paid a short visit to England and then published his "Travels in Chili and La Plata." In Brazil, where he subsequently resided eight years engaged in his profes. sional engineering labours, he made extensive collections of plants and insects. After his return to England he was elected a Fellow of the Linnean Society in 1839 and a Fellow of the Royal Society in 1843 , acting for a time on the Council of both societies. He contributed many papers of interest to the Linnean Society, and published the "Illustrations" and the "Contributions" to South American Botany. He served on the jury of the Brazilian Section of the Exhibitions of 1862, and of 1867 of Paris, and for his labours the Emperor conferred on him the honour of Commander of the Order of the Rose. His zeal and energy in his pursuits were most untiring, and he only desisted from his labours when forced by failing health in July last, since which time he gradually became weaker, till death ended his life on the $I 7$ th inst. in the ninety-first year of his age. It is understood that $\mathrm{Mr}$. Miers has left his botanical collections to the British Museum.

As a botanist, Mr. Miers was most painstaking and accurate in his investigation of details. His descriptions, and especially his original drawings, afford ample evidence of this. On the other hand, his estimate of the relative value of the details he elaborated with such zeal and care was often at fault. His observation was keen and accurate, but his judgment was less to be relied on. It is on this account, probably, that multitudes of species and, in lesser numbers, genera, and even orders, proposed by him, have not been generally accepted by his brother naturalists. Mr. Miers, we believe, never adopted evolutionary views, but remained a believer in the fixity of specific types. What, however, is more remarkable is that to the last he disbelieved in the action of the pollen and of the pollen tube in the formation of the embryo plant. In this particular Mr. Miers probably stcod alone: among his fellows.

But whatever difference of opinion may exist as to the value of his inferences, there can be none as to the laborious accuracy of his descriptions, the fidelity and beauty of his drawings (too often spoiled in the reproduc. tion), and the generous kindliness of the man.

\section{NOTES}

M. Raoul Pictet has been appointed Professor of Physics by the Council of State of Geneva, at the University of his native city.

M. KRANTz, the director of the Paris Exhibition of 1878 , is publishing the lectures delivered at the Trocadero. It will consist of no less than thirty-five thick 8 vo volumes, five of which have already gone through the press.

A $T$ the meeting on October 7 of the Manchester Literary and Philosophical Society, the president, Dr. Joule, described a simple means for checking the oscillations of a telescope. It consisted of a leaden ring placed centrally about the axis of the. 